\title{
Relationship between early proteinuria and long term outcome of kidney transplanted patients from different decades of donor age
}

Davide Diena ${ }^{1 \dagger}$, Maria Messina ${ }^{1 \dagger}$, Consuelo De Biase ${ }^{1}$, Fabrizio Fop ${ }^{1}$, Edoardo Scardino ${ }^{1}$, Maura M. Rossetti ${ }^{1}$, Antonella Barreca ${ }^{2}$, Aldo Verri ${ }^{3}$ and Luigi Biancone ${ }^{1 *}$

\begin{abstract}
Background: Proteinuria after kidney transplantation portends a worse graft survival. However the magnitude of proteinuria related to patient and graft survival and its correlation with donor and recipient characteristics are poorly explored.

Methods: This study investigated the impact of post transplant proteinuria in the first year in 1127 kidney transplants analyzing the impact of different donor ages. Proteinuria cut off was set at $0.5 \mathrm{~g} /$ day.

Results: Transplants with proteinuria $\geq 0.5 \mathrm{~g}$ /day correlated with poor graft and patient outcome in all donor age groups. In addition, 6-month-1-year proteinuria increase was significantly associated with graft outcome, especially with donors $\geq 60$ years old ( $p<0.05$; Odd Ratio 1.8). 1-year graft function (eGFR $<$ or $\geq 44 \mathrm{ml} / \mathrm{min}$ ) had similar impact to proteinuria ( $\geq 0.5 \mathrm{~g}$ /day) on graft failure (Hazard Ratio 2.77 vs Hazard Ratio 2.46). Low-grade proteinuria $(0.2-0.5 \mathrm{~g} /$ day) demonstrated a trend for worse graft survival with increasing donor age. Also in kidney-paired analysis proteinuria $\geq 0.5$ effect was more significant with donors $\geq 50$ years old (Odd Ratio 2.3).

Conclusions: Post-transplant proteinuria was increasingly harmful with older donor age. Proteinuria $\geq 0.5 \mathrm{~g} / \mathrm{day}$ correlates with worse outcomes in all transplanted patients. Prognostic value of proteinuria and eGFR for graft and patient survival was comparable and these two variables remain significant risk factors even in a multivariate model that take into consideration the most important clinical variables (donor age, rejection, delayed graft function and cytomegalovirus viremia among others).
\end{abstract}

Keywords: Kidney transplantation, Elderly donors, Proteinuria, Long-term outcome, Estimated glomerular filtration rate

\section{Background}

Over the past decades, increase of donor pool by using elderly donors has been largely adopted to reduce kidney transplant (KT) waiting list [1]. "Old for old strategy" allowed a better allocation of kidneys matching the life expectancy of organs and recipients [2], even if elderly kidneys have been shown to have a compromised renal

\footnotetext{
* Correspondence: luigi.biancone@unito.it

${ }^{\dagger}$ Davide Diena and Maria Messina contributed equally to this work.

${ }^{1}$ Renal Transplant Center "A. Vercellone", Nephrology, Dialysis and Renal Transplant Division, "Città della Salute e della Scienza Hospital", Department of Medical Sciences, University of Turin, Corso Dogliotti14, 10126 Torino, Italy Full list of author information is available at the end of the article
}

reserve and more proclivity to nonspecific damages. Those conditions (in particular through ischemia-reperfusion damage and delayed graft function -DGF-) increase the immunologic risk of such organs either through enhanced immunogenicity or through compromised repair mechanisms [3]. Nevertheless, death censored graft survival does not change among donor decades if a correct allocation policy is performed [4].

Proteinuria is known to be an independent risk factor for cardiovascular disease and mortality in native kidneys as well as an indicator of renal damage and a predictor of allograft loss after kidney transplantation [5, 6]. Several

(c) The Author(s). 2019 Open Access This article is distributed under the terms of the Creative Commons Attribution 4.0 International License (http://creativecommons.org/licenses/by/4.0/), which permits unrestricted use, distribution, and 
studies in the past years speculated that the optimal timing for measuring proteinuria to detect ongoing damage and to adopt specific strategies to prevent its progression is between 3 months and one year post-KT [7-12].

Even if older donor age is mentioned as risk factor for development of post-KT proteinuria $[8,13]$, the effective impact of proteinuria in recipients of elderly donors is not clearly defined and studied. Moreover, in the great majority of the studies, mean donor age is far younger (on average 45 years) than in cohorts with prevalence of non-standard donors.

Halimi and coworkers showed a strong correlation of 1 - and 3-month proteinuria (per every $0.1 \mathrm{~g} /$ day increase) with graft loss [7]. Amer and colleagues analyzed 1-year post KT proteinuria finding an Hazard Ratio (HR) for graft loss of 2.15 (CI 95\% 0.68-6.8), associated with proteinuria between 150 and $500 \mathrm{mg} /$ day and an HR of 5.11 (CI 95\% 1.4-19.2) with higher level of proteinuria [9].

In a recent study Naesens et al. found a strong direct correlation between 1-year post KT proteinuria and graft loss irrespectively from graft histology, but only for proteinuria values higher than $1 \mathrm{~g} /$ day (HR 2.17) [6]. In the study by Cantarovich and coworkers, proteinuria $>0.5 \mathrm{~g} /$ $\mathrm{d}$, at 3-month and 2-year post-KT was a significant prognostic marker of graft outcome. At 5-years, this significance was not observed [14].

To the best of our knowledge, only one available study is specifically focused on proteinuria impact on transplants from Extended Criteria Donors, although on a relatively small sample size and without comparison with standard donors [15].

Aim of this study was to analyze the impact of different degrees of 1-year proteinuria on patient and graft survival in kidney transplants from different donor ages and to evaluate the correlation between proteinuria and donor or recipient risk factors with graft loss. A secondary aim is to evaluate proteinuria as risk factor for kidney graft survival in multimodal models taking into account renal function and other main clinical variables.

\section{Methods}

\section{Study design}

We performed a retrospective observational cohort study including all deceased donor grafts performed at Turin University Renal Transplant Center "A. Vercellone" from January 2003 to December 2013. The study was submitted and approved by the local ethics committee (ethics committee of "Azienda Ospedaliera Universitaria Città della Salute e della Scienza di Torino"/ University of Turin). To exclude confounding factors and homogenize study populations we excluded multiorgan grafts analyzing the remaining 1127 consecutive kidney transplants $(\mathrm{KT})$.
Immunosuppressive regimen differed according to different transplantation eras and different populations. Briefly, the most adopted schedules were: induction with steroid boluses, rapidly tapered to $20 \mathrm{mg} /$ day of oral prednisone and two doses of anti-CD25 antibody (Simulect ${ }^{\circ}$, Novartis, Basel, Switzerland). Subjects at high immunological risk (e.g. previous transplant lost for acute rejection, high PRA titer) were treated with antithymocyte globulin (Thymoglobuline ${ }^{\circ}$, Genzyme, Cambridge, USA). Maintenance therapy was generally based initially on a triple-drug protocol. Calcineurin inhibitor (CNI), either tacrolimus (80\% of cases) or Cyclosporine, was associated to Mofetil Micofenolate (Cell $\mathrm{Cept}^{\circ}$, Roche, Basel, Switzerland)/Micophenolic Acid (Myfortic ${ }^{\circ}$, Novartis, Basel, Switzerland) or Azathioprine and prednisone. In KT from Extended Criteria Donors, CNI administration was, in most cases, delayed until serum creatinine reached $2.5 \mathrm{mg} / \mathrm{dl}$ to reduce the impact of nephrotoxicity, as we previously published $^{15}$. CNI levels were targeted on the basis of patients' characteristics, KT time and transplant eras; for the vast majority of patients, target plasmatic tacrolimus levels were: $10-15 \mathrm{ng} / \mathrm{ml}$ in the first two months, $8-10 \mathrm{ng} / \mathrm{ml}$ up to the sixth month, $5-8 \mathrm{ng} / \mathrm{ml}$ up to the first two years. Steroid was tapered to $5 \mathrm{mg}$ /day within 45-60 days and subsequently withdrawn in selected patients. Micofenolate dose reduction and discontinuation were performed when appropriate after hospital discharge. Mammalian target of Rapamycin-inhibitors (mTORi), combined or not with low doses CNI, were used in selected cases (anamnestic/active malignancies, $\mathrm{CNI}$ intolerance, biopsy-proven severe $\mathrm{CNI}$ toxicity) with a switch generally after the sixth post-transplant month.

The recipients' follow-up was performed with scheduled clinical visits for the entire follow-up and hospital admissions when major complications occurred. Data were collected from patients' individual charts: creatinine and proteinuria (in 24-h urine collections) were assessed at discharge, at 3,6 months and at 1,2 and 5 years after transplantation. Renal allograft function (eGFR) was estimated by Chronic Kidney Disease Epidemiology Collaboration (CKD-EPI) equation. Pre-transplant donor biopsies were performed on the basis of a multidimensional assessment including macroscopic appearance, renal function, donor comorbidities and echographic characteristics [4]. In detail: in the great majority of cases biopsy is usually not performed in donors $<50$ years and always performed in donors older than 70 years. For donors with age $50-70$ several characteristics are taken into consideration including donor cerebrovascular cause of death in the absence of vascular malformation, echographic parameters (renal cortex thickness, renal longitudinal diameter, longitudinal diameter discrepancy between the two kidneys), donor 
hypertension, donor diabetes, donor active smoking, donor proteinuria $>100 \mathrm{mg} / \mathrm{dl}$ at urinalysis.

Post-transplant renal biopsies were performed for cause (mainly when serum Creatinine increased $\geq 20 \%$ of baseline value or with proteinuria $>$ of $0.5-1 \mathrm{~g} /$ day). A single group of trained pathologists, through the whole study period, analyzed all pre-transplant and posttransplant kidney biopsies. Follow-up ended on November 2017. Karpinsky score was used to define suitability for single or dual KT or refusal of organs.

Patients were divided in 3 groups according to donor age: group A ( $<50$ years), group B (50-69 years), group $\mathrm{C} \geq 70$ years. The outcomes were analyzed for patients with at least 1 year of follow-up according to 1 -year post-KT extent. To eliminate confounding factors, as native kidneys proteinuria, we mainly explored proteinuria values after the sixth post-KT month; when comparing 6-month and 1-year proteinuria (1-year PTO), the latter showed a better correlation with death censored graft survival (DCGS) with an AUC 0.64 vs 0.59 (Fig. 1).

Regarding 1-year PTO we used a cut-off based on clinical considerations and previous literature data $(0.5 \mathrm{~g} /$ day). On the basis of median value of proteinuria in our cohort we further analyze low-grade proteinuria (between $0.2 \mathrm{~g} /$ day and $0.5 \mathrm{~g} /$ day). Similarly,eGFR value at 1 -year post-KT showed the best correlation with DCGS (AUC 0.74) (Fig. 2) and its median value in the whole population was $44.24 \mathrm{ml} / \mathrm{min}$ (25st-75st percentiles, $32.92-58.77 \mathrm{ml} / \mathrm{min}$ ). Main outcomes were death censored graft survival (DCGS) and patient survival. Graft function and the occurrence of relevant post-KT complications were also analyzed.

A further paired kidney analysis was performed considering only cases where both kidneys from the same deceased donor were transplanted at our institution (370 recipients, 185 pairs); primary outcomes were evaluated in this subset as in general cohort.

\section{Ethics and consent to participate}

The study was submitted and approved by the local ethics committee (ethics committee of "Azienda Ospedaliera Universitaria città della Salute e della Scienza di Torino"/University of Turin) and was performed in adherence with the last version of the Helsinki Declaration. All patients allowed to have their clinical data collected for study purposes by written consent. The clinical and research activities being reported are consistent with the Principles of the Declaration of Istanbul as outlined in the "Declaration of Istanbul on Organ Trafficking and Transplant Tourism".

\section{Statistical methods}

Discrete data were described as percentages and analyzed with Pearson's $X^{2}$ or, for small samples, with Fisher's exact test. The distribution of continuous variables was analyzed with Kolmogorov-Smirnov test. Continuous variables were described as mean \pm standard deviation when normal and median with $25^{\circ}-75^{\circ}$ percentile when non-normal distributed. Mann-Whitney, KruskalWallis, t-test or variance analysis with Bonferroni post

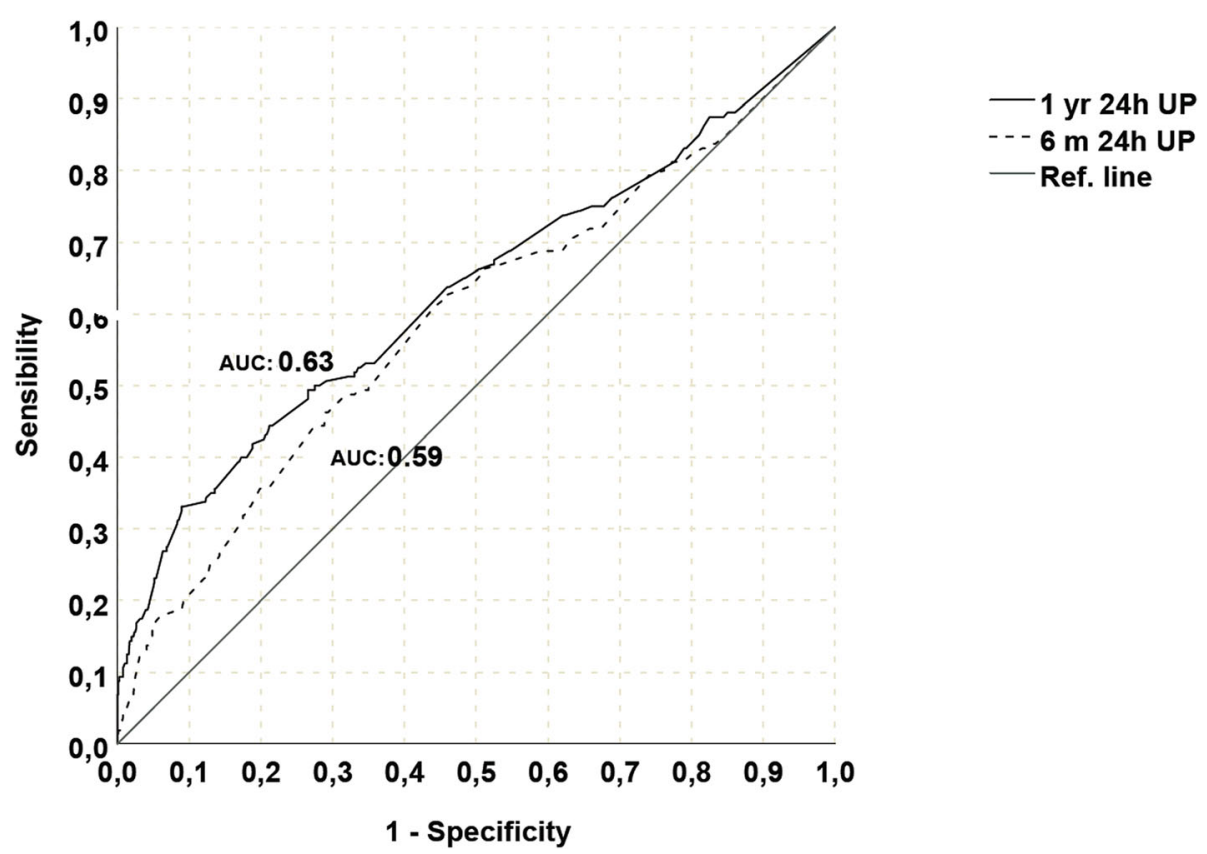

Fig. 1 ROC curves for association between 6-month and 1-year post kidney Transplantation proteinuria and death censored graft survival, $M=$ month, yr =year, $A \cup C=$ Area Under the curve, $U P=$ urinary protein 

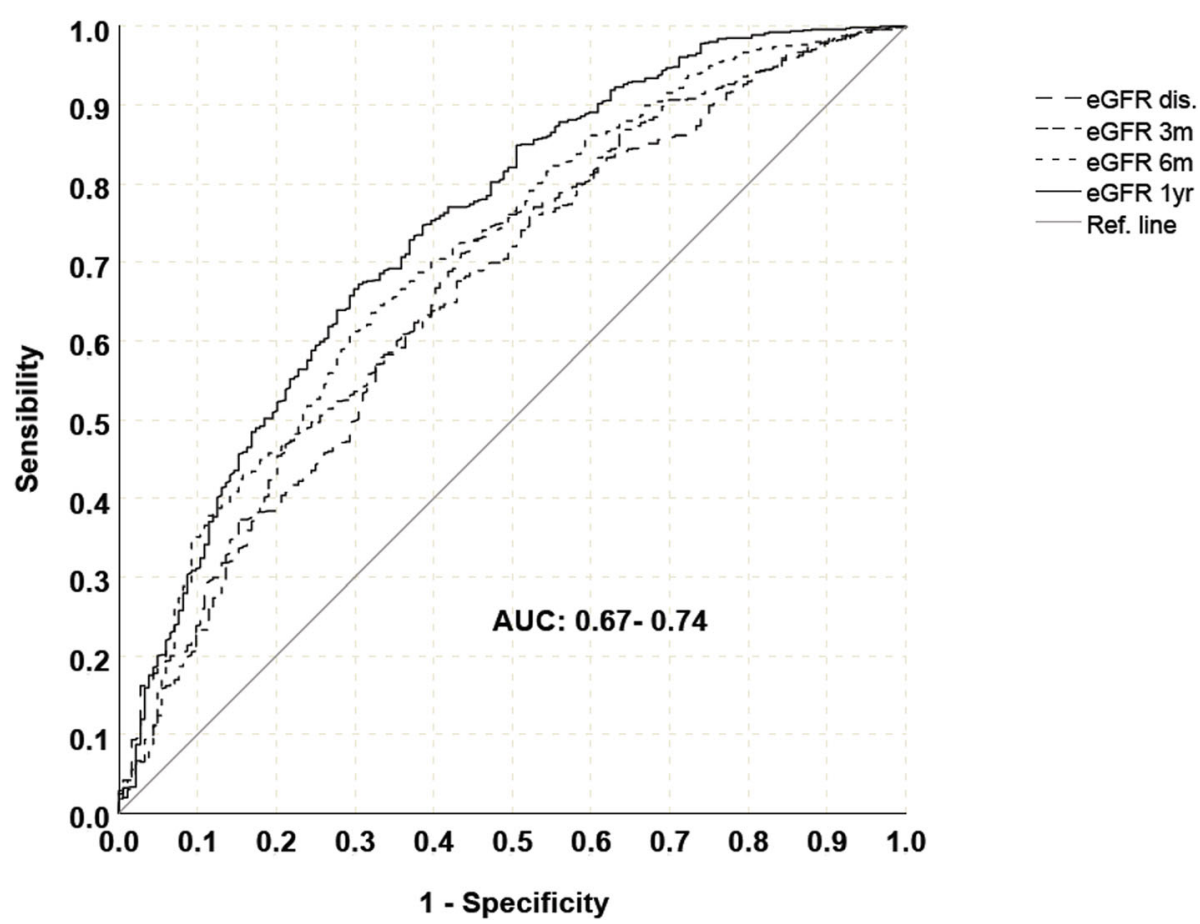

estimated glomerular filtration rate, dis = discharge, $m=$ month, $y=$ year, $A \cup C=$ Area Under the Curve

hoc test were used when appropriate to analyze difference between groups.

Receiving operating characteristic (ROC) curve and under the curve area (UCA) were used to illustrate the diagnostic ability of parameters chosen. We used UCA to determine the proteinuria time point with the strong association with DCGS.

Cumulative graft and patient survival were analyzed by Kaplan-Meier (KM) curves.

We fitted univariate model for main clinically chosen covariates (1- year proteinuria, donor age, recipient age, eGFR, DGF, rejection, 1 year Cytomegalovirus (CMV) infection) and we identified predictors as significant at level $\alpha=0.05$ (log rank test). Then we fitted a multivariate model with univariate predictors using stepwise with $p$-value $<0.05$ as entry criterion and $\mathrm{p}$-value $>0.10$ as removal criterion.

All statistical analyses were performed using Spss (IBM SPSS Statistics, vers. 25.0.0). Significance level for all tests was set at $\alpha<0.05$.

\section{Results}

Our analysis included 1127 kidney recipients, transplanted at Turin University Renal Transplant Center "A. Vercellone" between January 2003 and December 2013. The selected population was classified by donor age: group A (less than 50 years old) including 339 patients, group B (50-69 years old) including 496 patients and group $C$ (more than 70 years old, with a maximum age of 88 years) including 292 patients. Main donor, recipient and transplant-associated characteristics are shown in Table 1. Mean follow-up was 8.21 years (25th-75th percentiles: $5.38-11.43$ years).

Assuming $0.5 \mathrm{~g} /$ day as proteinuria cut-off, the association of 1-year PTO with DCGS and graft survival was present for all donor age classes (Table 2); the impact of proteinuria on patient survival was noted only for younger donors. Donor age increased the magnitude of proteinuria impact: DCGS of patients with donor age $\geq 70$ years and higher 1 -year proteinuria was only $29.7 \%$ versus $72.3 \%$ in recipients of kidneys from younger donors with the same proteinuria $(p=0.03)$.

As we noticed that median value of proteinuria in our population was nearly $0.2 \mathrm{~g} /$ day, we explored the impact of low grade proteinuria $(0.2-0.5 \mathrm{~g} /$ day $)$ compared with proteinuria $<0.2 \mathrm{~g} /$ day in the whole cohort and in different donor ages. In the low grade proteinuria group univariate analysis did not show any significant association of 1-year PTO with patient and graft survival and DCGS at any donor age. Yet, a definite (not significant) trend was evident for donors $\geq 70$ years, regarding graft and DCGS (DCGS $82.3 \%$ with 1 -year proteinuria $<0.2 \mathrm{~g} /$ day vs $65.3 \%$ with 1 year proteinuria $0.2-0.5 \mathrm{~g} /$ day; $p=0.09$ ) Fig. 3 .

In order to investigate whether other donor factors could be related with post-KT proteinuria, Karpinsky 
Table 1 Donor, Recipient and Transplant baseline characteristics by donor age $<50$ years between 50 and 69 years and $\geq 70$ years

\begin{tabular}{|c|c|c|c|c|c|}
\hline & $\begin{array}{l}\text { All patients } \\
\text { (1127 pts) }\end{array}$ & $\begin{array}{l}\text { Donors < } 50 \text { yrs. } \\
\text { (339 pts) }\end{array}$ & $\begin{array}{l}\text { Donors 50-69yrs. } \\
\text { (496 pts) }\end{array}$ & $\begin{array}{l}\text { Donors } \geq 70 \text { yrs. } \\
\text { (292 pts) }\end{array}$ & $P$ value \\
\hline \multicolumn{6}{|l|}{ 1A - Donor characteristics } \\
\hline$M / F(\%)$ & $578 / 549(51 / 49)$ & 215/124 (63/37) & $229 / 267(46 / 54)$ & $134 / 158(46 / 54)$ & $<0,01$ \\
\hline eGFR CG (ml/min) & 99,38 & $126,89 \pm 40,65$ & $94,68 \pm 34,83$ & $76,78 \pm 28,22$ & $<0,01$ \\
\hline eGFR CKD-EPI(ml/min) & 83,65 & $103,51 \pm 30,39$ & $85,79 \pm 25,38$ & $79,7 \pm 22,03$ & $<0,01$ \\
\hline Hypertension (\%) & $511(49)$ & $66(21)$ & $259(57)$ & $186(68)$ & $<0,01$ \\
\hline Diabetes mellitus (\%) & $78(8)$ & $9(3)$ & $49(12)$ & $20(8)$ & $<0,01$ \\
\hline Cerebrovascular cause of death (\%) & $747(72)$ & $159(52)$ & $370(80)$ & $218(81)$ & $<0,01$ \\
\hline \multicolumn{6}{|l|}{ 1B - Recipient characteristics } \\
\hline M/F (\%) & $721 / 406(64 / 36)$ & $217 / 122(64 / 36)$ & $305 / 191(61 / 39)$ & 199/93 (68/32) & 0,18 \\
\hline Mean age (Yrs) & $59.17 \pm 9.43$ & $43,99 \pm 10,69$ & $55,31 \pm 9,66$ & $62,73 \pm 7,93$ & $<0,01$ \\
\hline 1st Tx/ More than $1 \mathrm{Tx}(\%)$ & $972 / 155(87 / 13)$ & $\begin{array}{l}277 / 62 \\
(82 / 18)\end{array}$ & $427 / 69(86 / 14)$ & $\begin{array}{l}268 / 24 \\
(92 / 8)\end{array}$ & $<0,01$ \\
\hline SKT/DKT (\%) & $\begin{array}{l}1082 / 45 \\
(96 / 4)\end{array}$ & $\begin{array}{l}339 / 0 \\
(100 / 0)\end{array}$ & $481 / 15(97 / 3)$ & $\begin{array}{l}262 / 30 \\
(90 / 10)\end{array}$ & $<0,01$ \\
\hline HD/PD (\%) & $873 / 308(79 / 28)$ & $279 / 73(86 / 22)$ & $390 / 136(80 / 28)$ & 204/99 (71/35) & $<0,01$ \\
\hline Pretransplant DM 1 or 2/type 2 (\%) & $95 / 79(10,2 / 7)$ & $19 / 14(6 / 4)$ & $48 / 35(10 / 7)$ & $16 / 30(16 / 11)$ & $<0,01$ \\
\hline Pretransplat Hypertension (\%) & $939(86)$ & $267(81)$ & $420(88)$ & $252(91)$ & $<0,01$ \\
\hline Pretransplant Cardiopathy (\%) & $358(32)$ & $90(26)$ & $164(33)$ & $104(36)$ & $<0,01$ \\
\hline Pretransplant HCV POS (\%) & $91(8)$ & $26(8)$ & $44(9)$ & $21(8)$ & 0,78 \\
\hline \multicolumn{6}{|l|}{ 1C - Transplant characteristics } \\
\hline HLA A/B/DR MM (0-2/3-4/5-6) \% & $48 / 46 / 6$ & $32 / 62 / 6$ & $34 / 57 / 9$ & $42 / 54 / 4$ & 0,27 \\
\hline PRA zero (CDC) at transplantation \% & 66,3 & 63 & 63 & 75,4 & 0,13 \\
\hline Cold ischemia time (hours) & $16,16 \pm 5,22$ & $15,89 \pm 5,37$ & $17,80 \pm 4,98$ & $18,25 \pm 4,64$ & 0,03 \\
\hline DGF (\%) & $298(28)$ & $74(23)$ & $135(29)$ & $89(32)$ & 0,04 \\
\hline Induction Therapy & & & & & $<0,01$ \\
\hline ATG (\%) & $21(2)$ & $3(1)$ & $3(1)$ & $9(3)$ & \\
\hline Basiliximab (\%) & $1080(98)$ & $319(98)$ & $479(98)$ & $282(99)$ & \\
\hline Mantaining Therapy & & & & & $<0,01$ \\
\hline Tacrolimus (\%) & $848(79)$ & $286(87)$ & $360(77)$ & $202(73)$ & \\
\hline Cyclosporine (\%) & $181(17)$ & $32(10)$ & $95(20)$ & $54(20)$ & \\
\hline mTORi (\%) & $83(8)$ & $27(11)$ & $31(7)$ & $25(9)$ & \\
\hline mTORi at $1 \mathrm{yr}(\%)$ & $169(15)$ & $77(23)$ & $59(12)$ & $33(11)$ & $<0,01$ \\
\hline ACE/ARB (\%) & $368(33)$ & $190(56)$ & $117(24)$ & $61(21)$ & $<0,01$ \\
\hline End f-up Mantaining Therapy (\%) & & & & & $<0,01$ \\
\hline Tacrolimus (\%) & $839(78)$ & $271(83)$ & $374(79)$ & $194(69)$ & \\
\hline Cyclosporine (\%) & $133(12)$ & $27(8)$ & $64(13)$ & $42(15)$ & \\
\hline mTORi (\%) & $255(24)$ & $56(17)$ & $124(26)$ & $73(26)$ & \\
\hline
\end{tabular}

eGFR = estimated Glomerular filtration rate; CG = Cockroft-Gault formula; CKD-EPI = Chronic Kidney Disease Epidemiology Collaboration; SKT = Single Kidney Transplantation; DKT = Dual Kidney Transplantation; PD = Peritoneal Dialysis; HD = Haemodialysis; DM = Diabetes Mellitus; HCV = Hepatitis C virus; HLA = Human Leucocyte Antigens; $M M=$ Mismatch; PRA = Panel Reactive Antibodies; $C D C=$ Cell Dependent Cytotoxicity; $A T G=$ anti-thymocite globulin; $m$ TORi = mammalian target of rapamycin inhibitors; $\mathrm{ACE}=$ angyotensin converting enzyme; $\mathrm{ARB}=$ Angiotensin Receptor Blockers; $\mathrm{DGF}=$ delayed graft function

score was evaluated when pre-implantation biopsies were available $(n=567)$, together with various factors (hypertension, diabetes, cause of death, serostatus for $C$ hepatitis).

In particular, regarding histology, we analyzed the distribution of total Karpinsky score in recipients of single
$\mathrm{KT}$ and in different donor age groups finding a significant difference ( $p<0.05$; data not shown). Moreover we analyzed distribution of total Karpinsky score in different one-year proteinuria groups (< or $\geq 0.5 \mathrm{~g} /$ day) without finding significant differences ( $p=0.59$; data not shown), 
Table 2 Patient, graft and death censored 10-year graft survival by different 1-year proteinuria and by different donor age classes

\begin{tabular}{|c|c|c|c|}
\hline 10-years survival \% & 1 -year pto $<0,5 \mathrm{~g} /$ day & 1-year pto $\geq 0,5 \mathrm{~g} /$ day & $P$ value \\
\hline \multicolumn{4}{|l|}{ All donor age classes } \\
\hline Patient & 87 & 81,3 & 0,02 \\
\hline Graft & 76.4 & 44.4 & $<0,01$ \\
\hline DCGS & 85.6 & 49.7 & $<0,01$ \\
\hline \multicolumn{4}{|l|}{ Donor $<50$ years } \\
\hline Patient & 96,9 & 79,6 & $<0,01$ \\
\hline Graft & 90.6 & 65.9 & $<0,01$ \\
\hline DCGS & 93.6 & 72.3 & $<0,01$ \\
\hline \multicolumn{4}{|l|}{ Donor 50-69 years } \\
\hline Patient & 86,9 & 87,9 & 0,67 \\
\hline Graft & 74.9 & 43.1 & $<0,01$ \\
\hline DCGS & 84.4 & 48.2 & $<0.01$ \\
\hline \multicolumn{4}{|l|}{ Donor $\geq 70$ years } \\
\hline Patient & 71,2 & 71,6 & 0,44 \\
\hline Graft & 56.2 & 25.9 & $<0,01$ \\
\hline DCGS & 75,2 & 29.7 & $<0,01$ \\
\hline
\end{tabular}

while a higher glomerulosclerosis score showed a good correlation with a higher 1-year proteinuria $(p=0.04)$. Nevertheless, total Karpinsky score as well as glomerulosclerosis score were not associated with DCGS differences.

We also performed another analysis splitting population under study by donor age and by one-year proteinuria but again we found no correlation between total Karpinsky score and DCGS in any of group analyzed.

We further took into consideration, short-term variation of proteinuria between 6-month and 1-year post-KT (6mo-1 yr proteinuria): in $44.0 \%$ of patients proteinuria increased between these 2 time points while in $56.0 \%$ it remained stable or decreased. Median positive variation of proteinuria was $0.12 \mathrm{~g} /$ day $(19,8 \%$ of patients had an increase of proteinuria $\geq 0.1$ g/day) while median negative variation was $0.05 \mathrm{~g} /$ die (22.4\% of patients had a decrease of proteinuria $\geq 0.1$ g/day). Positive/negative variation values were comparable for different donor age groups.

$6 \mathrm{mo}-1$ yr proteinuria increase was not associated with patient survival at any donor age $(p=0.71)$ (Fig. 4). On the contrary, any increase of proteinuria between these time points was associated with poor graft survival and DCGS (AUC 0.6; OR 1.8 - CI 95\% 1.2-2.5).

Again, this correlation was stronger when graft and DCGS were considered in recipients of elderly donors (Fig. 4). The different time to graft failure between donor age groups, respectively 6 years (CI 3-9 years) in group A vs 3 years (CI $1-6$ years) in group C, can be considered an additional data in favor of the association between donor age and 6 mo- 1 yr proteinuria positive variation. Angiotensin Converting Enzyme inhibitors/ Angiotensin II Receptor Blockers (ACEi/ARB) therapy did not influence $6 \mathrm{mo}-1$ yr proteinuria variations.

Including only subjects with $6 \mathrm{mo}-1 \mathrm{yr}$ proteinuria stable or increasing $(n=558)$ we identified $0.1 \mathrm{~g} /$ day as $6 \mathrm{mo}-1 \mathrm{yr}$ proteinuria cut-off with the best association with DCGS (UCA 0.68).

Patients with increase in $6 \mathrm{mo}-1 \mathrm{yr}$ proteinuria higher than $0.1 \mathrm{~g} /$ day had lower DCGS if compared with patients with lower increase (10-year graft survival 69.9\% vs $90.2 \% ; p<0.01)$. That significant difference was confirmed irrespectively of donor age.

To test the role of a potential confounding factor, the same analysis was performed excluding patients mTor inhibitors treated at one year post transplantation $(n=$ $159)$. In the remaining patients, proteinuria impact $(\geq$ $0.5 \mathrm{~g} /$ day) was not associated with significant variation in DCGS in the different age classes in univariate analysis (data not shown).

Early adverse events (during first post KT year) were evaluated in the different proteinuria subpopulations (Table 3). As expected, 1-year post-KT proteinuria $>0.5$ $\mathrm{g} /$ day was associated with new onset diabetes (NODAT), glomerulonephritis and rejection. Notably, also transplant urologic complications and Cytomegalovirus (CMV) viremia had an association with proteinuria. Biopsies were significantly more frequent in patients with higher 1 year proteinuria.

To compare proteinuria and creatinine impact on graft survival, 1-year eGFR was also evaluated. 1-year eGFR 

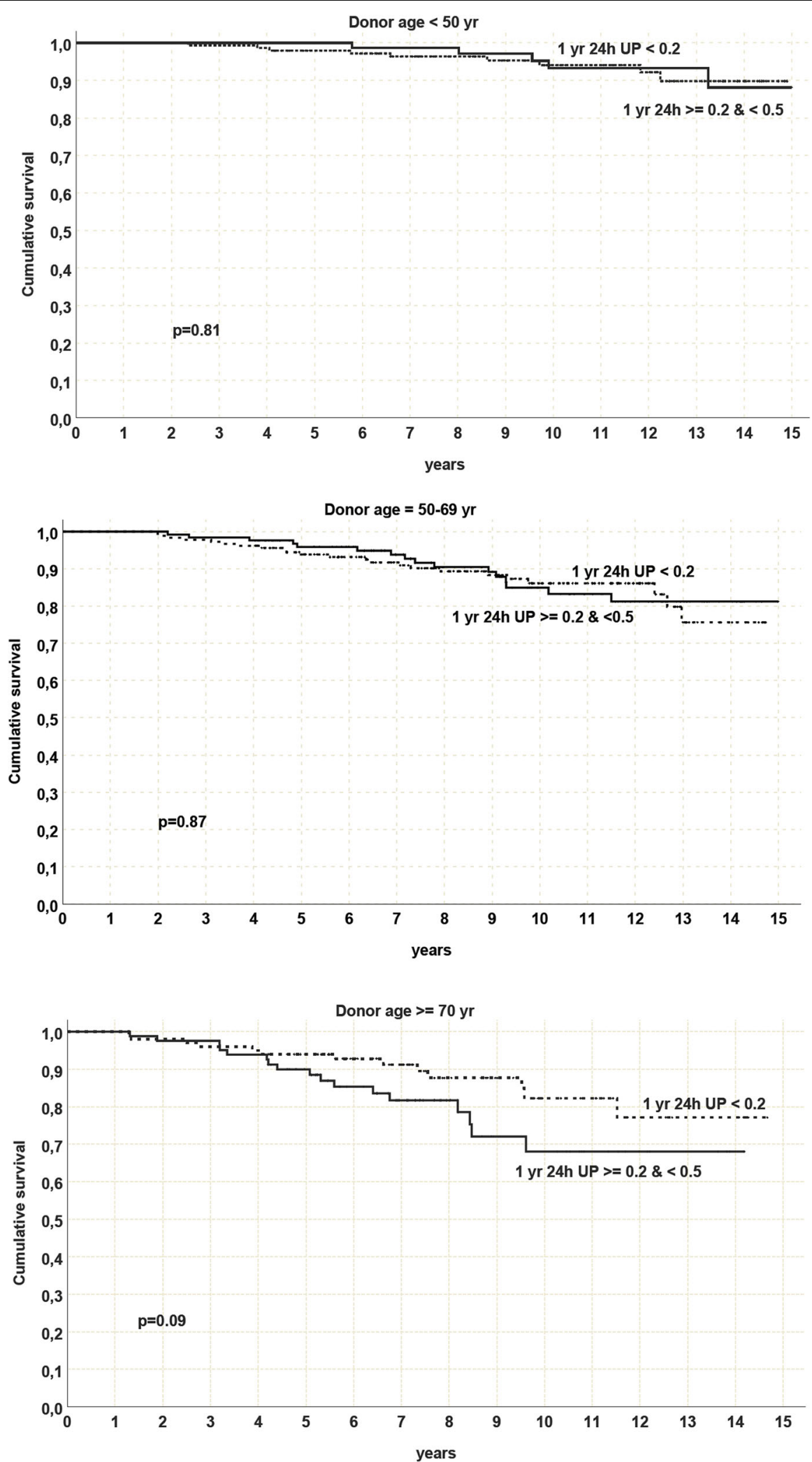

Fig. 3 Death censored graft survival in patient with 1-year proteinuria $0.2-0.5 \mathrm{~g} /$ day compared with proteinuria $<0.2 \mathrm{~g} /$ day in the whole population and by different donor age, $Y_{r}=$ year, UP = urinary protein 


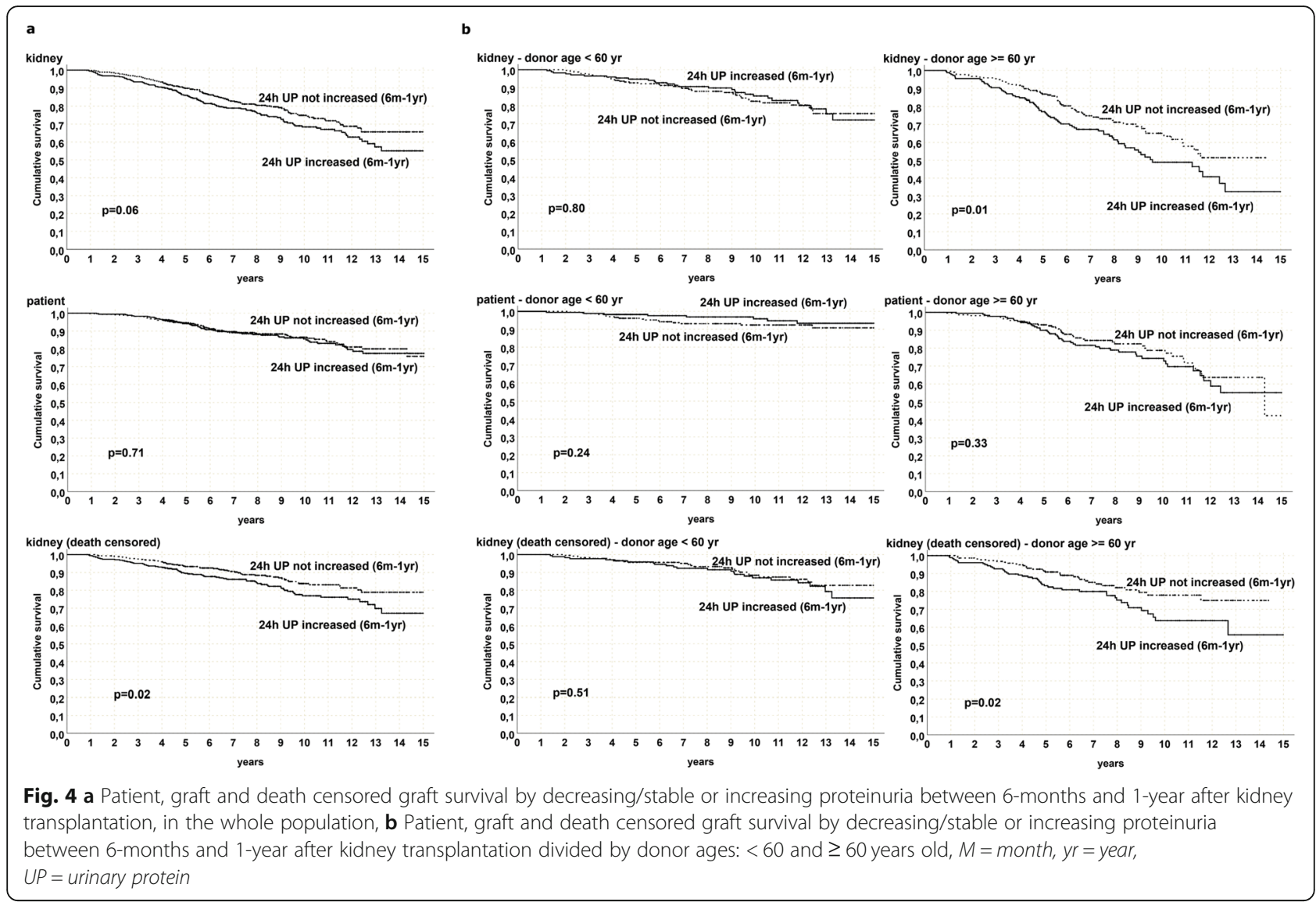

Table 3 Complications in the first year post-KT in the different group by 1-year proteinuria $<0,5 \mathrm{~g} /$ day and $\geq 0,5 \mathrm{~g} /$ day

\begin{tabular}{|c|c|c|c|c|}
\hline & All patients & 1 year $\mathrm{PTO}<0,5 \mathrm{~g} /$ day & 1 year $\mathrm{PTO} \geq 0,5 \mathrm{~g} /$ day & $P$ value \\
\hline \multicolumn{5}{|l|}{ Post transplant complications } \\
\hline DGF \% & 25,4 & 24,4 & 30,7 & $<0,05$ \\
\hline Transplant Urologic Complications \% & 30 & 28,3 & 38 & $<0,05$ \\
\hline Ureteral fistula \% & 3,8 & 3,1 & 7,0 & $<0,05$ \\
\hline Ureteral stenosis \% & 6,4 & 5,2 & 12,7 & $<0,05$ \\
\hline Transplant Vascular Complications \% & 15,5 & 14,6 & 19,7 & 0,12 \\
\hline Vascular fistula \% & 4,7 & 4,4 & 6,5 & 0,36 \\
\hline Renal artery stenosis \% & 9,4 & 9,0 & 11,5 & 0,18 \\
\hline Overall infection \% & 37,2 & 35,9 & 45,2 & 0,07 \\
\hline CMV infections \% & 24,2 & 22,3 & 34,4 & $<0,05$ \\
\hline Ischemic Cardiopathy \% & 7,9 & 8,3 & 5,7 & 0,33 \\
\hline NODAT \% & 21,2 & 19,7 & 29,3 & 0,01 \\
\hline Extrarenal Major Vascular Complications\%** & 2,6 & 2,5 & 3,2 & 0,68 \\
\hline Hypertension \% & 88 & 85 & 96 & 0,07 \\
\hline Rejection \% & 6,1 & 5,8 & 12,1 & $<0,05$ \\
\hline Biopsies \% & 26,9 & 23,1 & 55,4 & $<0,05$ \\
\hline Total Glomerulonephritis/Recurrent glomerulonephritis \% & $9,3 / 2,5$ & $7,3 / 1,7$ & $15,9 / 6,3$ & $<0,05$ \\
\hline
\end{tabular}

DGF = delayed graft function; $C M V=$ cytomegalovirus; NODAT = new onset diabetes after transplantation. Biopsies are all performed for cause *Including stroke, arterial stenosis and thrombosis 
was strongly associated to patient, graft and DCGS (91.2\% with eGFR $\geq 44 \mathrm{ml} / \mathrm{min}$ versus $65.2 \%$ with eGFR $<44 \mathrm{ml} / \mathrm{min} ; \mathrm{p}<0.01$ ) (Fig. 5).

Finally, in order to select the main predictors of DCGS, a multivariate model was created considering the most relevant clinical variables: 1-year proteinuria, donor age, recipient age, eGFR, DGF, rejection, 1-year CMV infection.

In this multivariate analysis (Table 4) 1 -year $\mathrm{PTO} \geq$ $0.5 \mathrm{~g} /$ day, donor age $\geq 70$ years, 1 -year eGFR $<44 \mathrm{ml} /$ min and the onset of CMV viremia in the first year were independently associated with DCGS. Rejection was a significant variable only when considered in the entire follow-up (not when 1st year rejections were considered).

Besides, on the basis of the heavy influence of donor age $\geq 70$ years on DCGS, we attempted a kidney paired study to eliminate donor characteristics contribution to the analysis and evaluate other potentially influencing factors. One hundred-eighty five kidney pairs, with both kidneys from the same donor transplanted in our Center, were selected and, among them, 43 couples with 1-year proteinuria discrepancy (one graft with 1year proteinuria $\geq 0.5 \mathrm{~g} /$ day and the paired one with proteinuria $<0.5 \mathrm{~g} /$ day) were analyzed.

Also In this case a great impact on DCGS was found: DCGS was respectively $86.6 \%$ for recipients with proteinuria $<0.5 \mathrm{~g} /$ day and $51.9 \%$ for the twin kidney with proteinuria $>0.5 \mathrm{~g} /$ day; $p<0.01$. This impact was not relevant in recipient of donors $<50$ years while was greater with donors $\geq 50$ years Fig. 6 . Comparison of post-KT complications between the two groups confirmed a statistically higher rate of rejection and glomerulonephritis and greater number of biopsies in the group with 1 -year $\mathrm{PTO} \geq 0.5 \mathrm{~g} /$ day. No significant variation was noted between the groups for the other analyzed variables. (Table 5).

\section{Discussion}

For the general population, the risk of adverse outcomes (mortality, progression to end-stage renal disease) increases with higher levels of albuminuria so that it was included in 2012 Kidney Disease Improving Global Outcomes guidelines as key marker for chronic kidney disease (CKD) [16].

Numerous studies in patients with diabetic and nondiabetic renal diseases confirm that marked albuminuria (>300 mg/day) is associated with a faster rate of CKD progression. On the contrary, moderate-level albuminuria $(150-300 \mathrm{mg} /$ day) is not a reliable surrogate marker for CKD progression in intervention clinical trials because reduction of albuminuria can be linked to both improving and worsening CKD progression $[17,18]$.
The deleterious impact of proteinuria, at relatively early post-KT time, on long-term outcome was clearly demonstrated in several previous studies $[6,7,9,14]$. Nevertheless, available studies differed in definition of post-KT harmful proteinuria as well as in post-KT considered time points. That uncertainty was reflected also by available guidelines for transplant management that suggest performing allograft biopsy when there is new onset proteinuria or unexplained proteinuria $3.0 \mathrm{~g} / \mathrm{mg}$ creatinine or $3.0 \mathrm{~g} / 24 \mathrm{~h}$, with a low level of evidence [19].

Evaluation of risk factors related to post-KT proteinuria was attempted in several studies finding a multitude of different donor-related, recipient related or transplant related factors including, among others, delayed graft function, greater body mass index at transplant, older donor age, greater HLA mismatch, tacrolimus use and antihypertensive use [13, 20].

Beyond the causes, however, the intrinsic risk of developing proteinuria at a relatively early stage (first post-KT year) should be addressed as a key risk factor for transplant outcome [21].

Our study demonstrated that occurrence of proteinuria, $(\geq 0.5 \mathrm{~g} /$ day $)$, at the first post-transplant year, was significantly linked to graft survival and patient survival in the whole population under study. For the first time in literature, to the best of our knowledge, the impact of proteinuria on KTs from different donor age classes was analyzed, demonstrating a synergic effect of proteinuria $\geq 0.5 \mathrm{~g} /$ day and donor age $\geq 70$ years on DCGS.

Very low grade proteinuria (between 0.2 and $0.5 \mathrm{~g} /$ day) was not related to outcome. Nevertheless, we demonstrated an association (a trend, not reaching significance) between DCGS and low-grade PTO $(\geq$ $0.2<0.5 \mathrm{~g} /$ day) only in kidneys from donors older than 70 years old. (Fig. 3).

Older donor kidneys seemed more sensitive to proteinuric injuries in comparison with younger ones with very relevant differences of DCGS in different donor age classes with same proteinuria. This is also highlighted by the fact that any variation of proteinuria between 6 months and 1 year post-KT portends a worse graft outcome when donor age was $\geq 60$ years (Fig. 4).

With ageing, kidney undergoes through processes that lead to reduced functional reserve and also to a lower renal reserve response to higher functional requests (e.g. protein load) due to a reduced capacity of renal autoregulation [22-25]. These functional changes, that could be also encountered in diabetic patients, were found to be associated with or precede microalbuminuria and glomerular lesions [26, 27]. Indeed, proteinuria is not considered to be a "normal" physiological process of aging also in cases when the development of a persistent proteinuria increases with age, due to the higher prevalence of diabetes, hypertension and paraproteinemias in the 
kidney

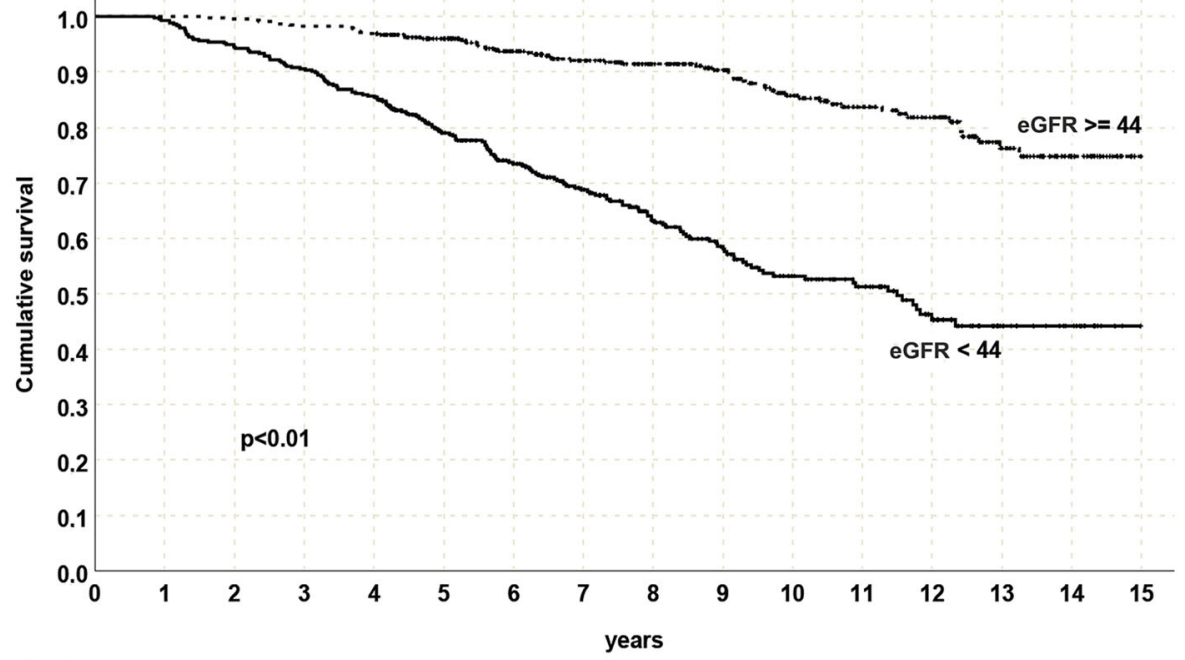

patient

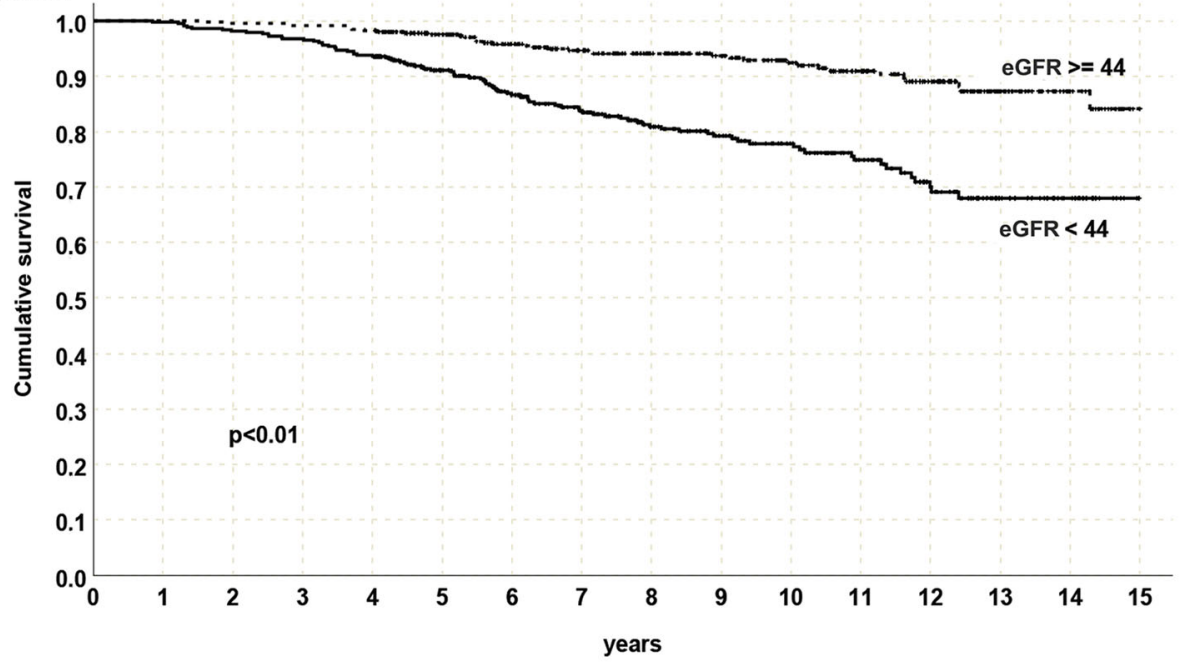

kidney (death censored)

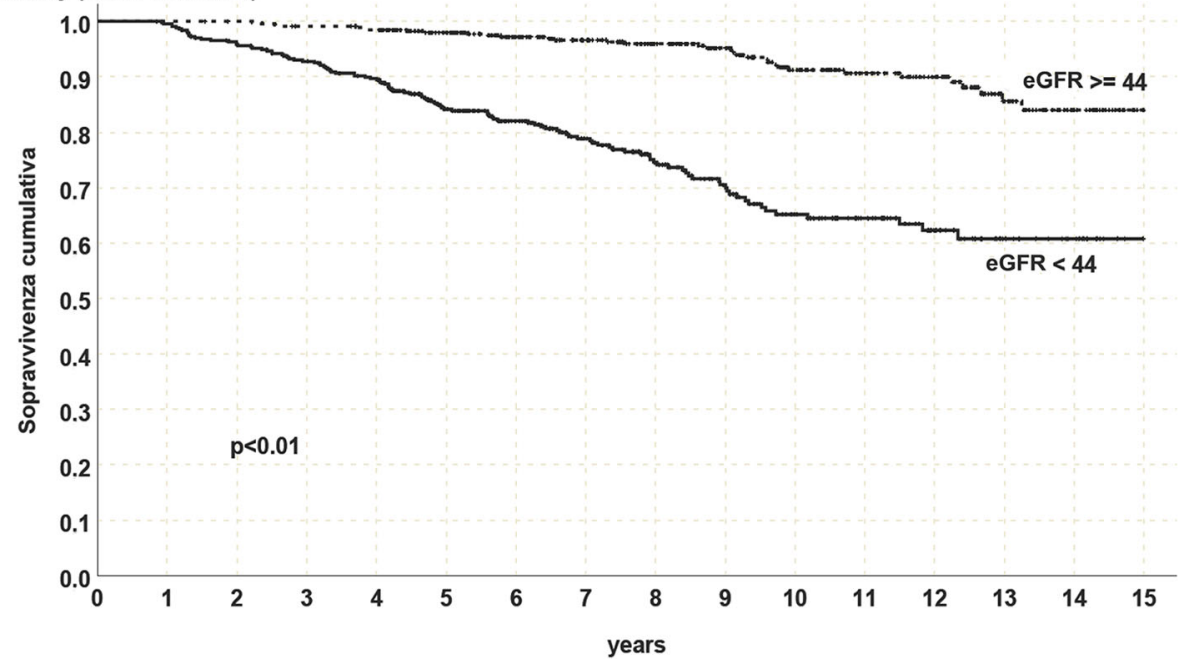

Fig. 5 Patient, graft and death censored graft survival with 1-year eGFR (CKD-EPI) $\geq$ or < of $44 \mathrm{ml} / \mathrm{min}$, eGFR= estimated glomerular filtration rate 

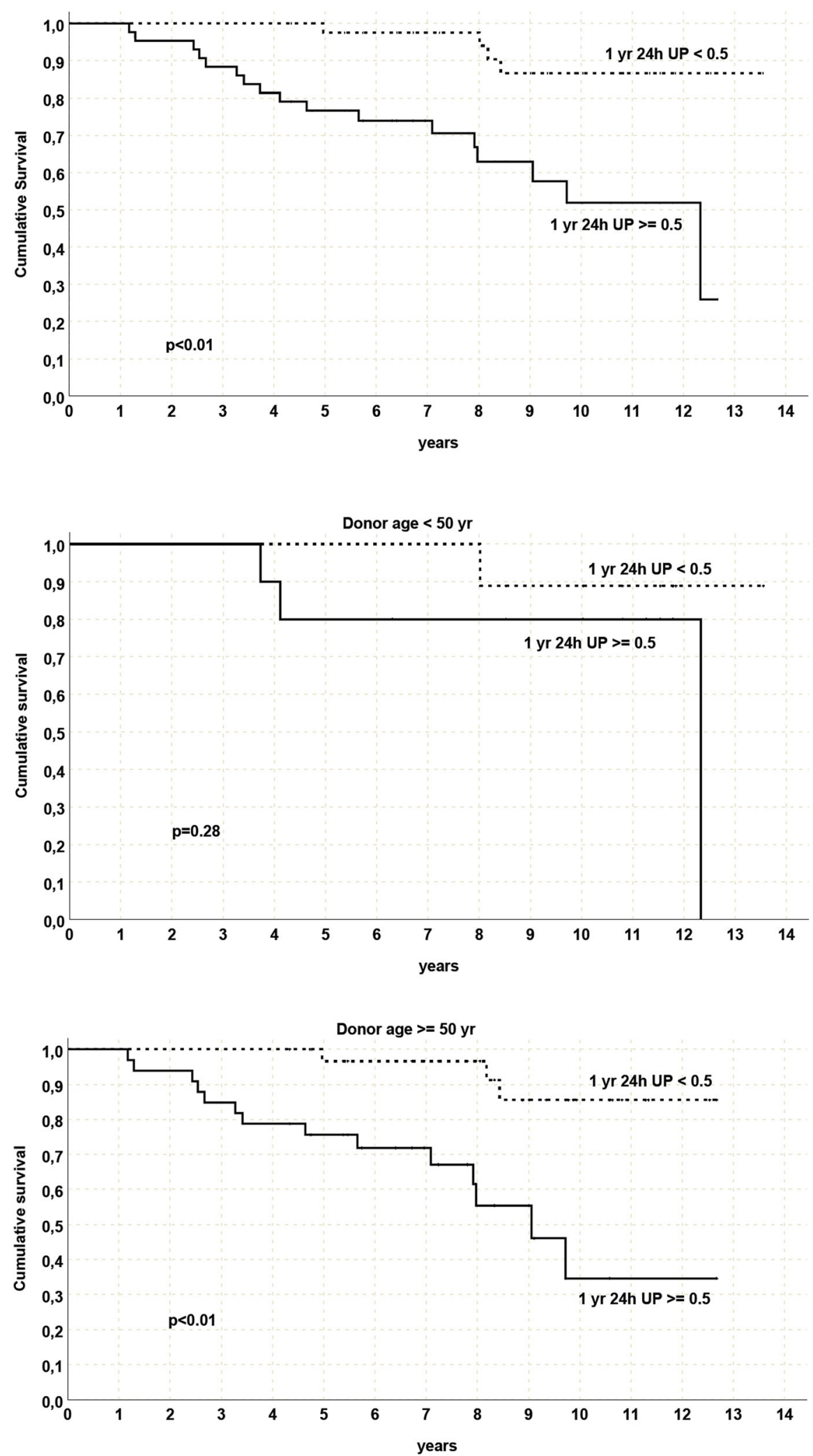

Fig. 6 Patient, Graft and Death censored graft survival analysis in kidney pairs with proteinuria $<0,5 \mathrm{~g} /$ day or $\geq 0,5 \mathrm{~g} /$ day in the whole population and divided by donor age $<50$ years or $\geq 50$ years, $Y r=$ year, UP $=$ urinary protein 
Table 4 Cox model for variables affecting graft outcome (death censored). Reference population is represented by recipients of donors $<50$ years

\begin{tabular}{lll}
\hline & P value & Hazard Ratio(Confidence interval 95\%) \\
\hline 1 -year proteinuria 0,2-0,5 g/day & 0.63 & $0,90(0.58-1,39)$ \\
1 -year proteinuria $\geq 0,5 \mathrm{~g} /$ day & $<0.01$ & $2,77(1,81-4,22)$ \\
1 -year eGFR $(C K D-E P I)<44 \mathrm{ml} / \mathrm{min}$ & $<0.01$ & $2,46(1,57-3,84)$ \\
Donor Age 50-69 years & 0,36 & $1,27(0,75-2,14)$ \\
Donor Age $\geq 70$ years & 0,029 & $1,85(1.06-3,21)$ \\
1 -year CMV viremia & $<0.01$ & $2105(1,47-3,00)$ \\
Rejection in the entire follow-up & $<0.01$ & $2,57(1,79-3,69)$ \\
\hline
\end{tabular}

CKD-EPI = Chronic Kidney Disease Epidemiology Collaboration, eGFR = estimated glomerular filtration rate, CMV = cytomegalovirus

elderly [28]. Therefore it could be speculated that the aforementioned process could be amplified in kidneys retrieved from elderly donors, which became more prone to several insults leading to compensatory hyperfiltration of glomeruli that survive reperfusion injury, rejection, and drug toxicity, and,in ultimate analysis, to a faster progression of renal damage. In this context, proteinuria is, at the same time, marker of damage progression and established loss of function, as witnessed by concordance between proteinuria grade and renal function in transplanted patients.

Predisposition to proteinuria development in our population appeared to be certainly related to both donor and recipient characteristics (donor age, pretransplant diabetes, glomerular Karpinsky score) but, as it is demonstrated by paired kidney analysis, early post-
KT events (acute rejection, CMV infections, new onset diabetes after transplantation and urological complications such as ureteral stenosis) contribute to determine kidney fate and prognosis. As shown in Table 3, rejections, number of biopsies, NODAT and glomerulonephritis were associated with higher 1-year PTO, surprisingly with similar distribution between donor age groups (data not shown); overall infections and CMV viremia as well as vascular and urological complications were, on the contrary, significantly more frequent in older donor population (data not shown). These data could be explained as a consequence of the indication for decreasing immunosuppressive therapy in case of infection and of the lower quality of older donor tissues in comparison with the younger donor kidneys $[29,30]$. Notably, we found a strong correlation between overall

Table 5 Complications in the first year post-KT in the pairs with different 1-year proteinuria $<0,5 \mathrm{~g} /$ day and $\geq 0,5 \mathrm{~g} /$ day

\begin{tabular}{|c|c|c|c|c|}
\hline & $\begin{array}{l}\text { Kidney pairs } \\
\text { (86 pts) }\end{array}$ & $\begin{array}{l}\text { Kidney twin with } 1 \text { year } \mathrm{PTO}<0,5 \mathrm{~g} / \mathrm{L} \\
(43 \text { pts) }\end{array}$ & $\begin{array}{l}\text { Kidney twin with } 1 \text { year PTO } \geq 0,5 \mathrm{~g} / \mathrm{L} \\
\text { (43 pts) }\end{array}$ & $P$ value \\
\hline \multicolumn{5}{|c|}{ Post-Transplant Complications in 1st post-KT year } \\
\hline DGF \% & $24(28)$ & $8(19)$ & $16(38)$ & 0,03 \\
\hline Transplant Urologic Complications \% & $48(56)$ & $23(53)$ & $25(58)$ & 0,41 \\
\hline Ureteral fistula \% & $3(3)$ & $1(2)$ & $2(5)$ & 0,5 \\
\hline Ureteral stenosis \% & $7(8)$ & $1(2)$ & $6(14)$ & 0,05 \\
\hline Transplant Vascular Complications \% & $19(22)$ & $11(26)$ & $8(19)$ & 0,3 \\
\hline Vascular fistula \% & $8(9)$ & $5(12)$ & $3(7)$ & 0,36 \\
\hline Renal artery stenosis \% & $9(10)$ & $4(9)$ & $5(12)$ & 0,5 \\
\hline Overall infections \% & $66(78)$ & $31(74)$ & $35(81)$ & 0,28 \\
\hline CMV infections & $29(34)$ & $13(30)$ & $16(37)$ & 0,32 \\
\hline Ischemic Cardiopathy & $7(8)$ & $5(12)$ & $2(5)$ & 0,22 \\
\hline NODAT & $22(26)$ & $9(21)$ & $13(30)$ & 0,32 \\
\hline Extrarenal Major Vascular Complications* & $18(21)$ & $10(23)$ & $8(19)$ & 0,60 \\
\hline Hypertension & $27(96)$ & $12(44)$ & $15(56)$ & 0,57 \\
\hline Rejection & $7(8)$ & $0(0)$ & $7(16)$ & $<0,01$ \\
\hline Biopsies (\%) & $51(65)$ & $18(49)$ & $33(80)$ & $<0,01$ \\
\hline Glomerulonephritis (\%) & $7(8)$ & $1(2)$ & $6(14)$ & 0,05 \\
\hline
\end{tabular}

DGF = delayed graft function; $C M V=$ cytomegalovirus; NODAT = new onset diabetes after transplantation. All Biopsies are performed for cause *Including stroke, arterial stenosis and thrombosis 
infection and rejection rates, especially when donor age was $>50$ years. Therefore, even if rejection risk seems to be similar in all donor ages, susceptibility to external factors (such as infections or urological/vascular complications) plays a major role in older donor populations.

It is well known that kidney allograft function in a stable condition (usually between 3 months and 1 year post $\mathrm{KT}$ ) is an important predictor of graft failure [31, 32]. One possible explanation is that, as in chronic kidney disease, lower kidney function is often associated with other cardiovascular risk factors (e.g. hypertension, dyslipidemia and smoke) predisposing to cardiovascular disease and mortality [33]. In our study (Table 4) we showed that 1 -year proteinuria $\geq 0.5 \mathrm{~g} /$ day (HR 2.77) is comparable to CKD-EPI $<44 \mathrm{ml} / \mathrm{min}$ (HR 2.46) in predicting graft failure by multivariate analysis. In this context, donor age $\geq 70$ years would make this association even worse.

Among the other clinical variables, CMV viremia post-transplant resulted as an independent predictor of DCGS in Cox multivariate analysis (HR 2.1), as mentioned in previous studies [34, 35]. As for rejection, when we consider rejection as an event in the entire follow-up, its role is comparable to the one of the other main risk factors (HR respectively 2.5 vs 2.1 and 2.4 ) (Table 4). This is not found for early rejections (1st year rejections) possibly because their role is somehow downsized in a context of a population of older donors and recipients in which other factors are probably more relevant.

Need for surrogate endpoints to enhance trial feasibility has been outlined by a recent review where proteinuria has been defined as a prognostic biomarker [36].

In the current scenario, the majority of available organs are represented by "suboptimal" donors (formerly known as ECD or with a Kidney Donor Profile Index greater than $85 \%$ according to the recent USA definition). Our study demonstrated prognostic significance of proteinuria, in particular with this kind of donors.

The link among proteinuria, donor age and subsequent higher proteinuria-mediated damage in older donors is an important issue of our study. Several mechanisms were advocated for proteinuria mediated tissue damage such as intratubular complement activation [37, 38], intratubular protein overload [39-41], radical oxygen damage induced by tubular reabsorption of iron carrying proteins such as transferrin [42]. Older donor kidneys may potentially be more sensitive to such mechanisms, even with a lower grade of proteinuria.

As mentioned in previous studies and confirmed by our data, the evidence suggesting a benefit for ACEi/ ARB use in transplant recipients is still lacking. They showed that the use of these agents was often associated with a significant reduction in proteinuria and eGFR without a concurrent improvement of patient or allograft survival as it does in non-transplant settings such as in diabetic nephropathy [43, 44]. This is also confirmed in a recent randomized controlled trial in which ramipril compared with placebo did not lead to a significant reduction in doubling of serum creatinine, endstage renal disease, or death in kidney transplant recipients with proteinuria. These data would not support widespread use of this drugs to obtain clinical improvement in transplanted patients [45].

It is well known that Mtor-inhibitors may induce proteinuria by targeting glomerular podocytes [46]. This is confirmed also in our cohort. However, excluding patients with mTor maintenance therapy in the first year (16\%), the impact of proteinuria on outcome was confirmed.

Our study has some strenghts and some limitations. Strenghts of the study are related to homogeneity of the population, characterized by a wide range of data coming from over a thousand of KTs performed with the same team of surgeons, nephrologists and pathologists. Patients were centrally followed in the long term with all data recorded in patients' charts.

Another strength, in our opinion, is the validation of prognostic impact of proteinuria in a subset of paired kidneys, thus limiting undetermined donor-derived confounding factors [47].

We acknowledge that a limitation of this study is the absence of protocol graft biopsies for center policy; however, this limitation reduces its importance when we consider that proteinuria impact was shown by some authors to be independent from the underlying renal allograft histology [6].

Other limitations are: absence of routinely donor specific antibody evaluation in the first year, which was available only in a minority of patients, so that we did not evaluate our population under this aspect; moreover lack of qualitative differentiation of urinary protein, considering that tubular or glomerular proteinuria could have different impact on graft outcome, as underlined in previous studies [11, 48, 49].

\section{Conclusions}

If it is unlikely that a single noninvasive biomarker will yield a high predictive performance for graft loss, it is however auspicable a correlation of post-KT proteinuria trajectories with clinical events to guide clinical measures. Clinicians often do not know how to handle early low-grade proteinuria given the fact that it is often considered as aspecific, possibly due to native kidneys residual function (in the early period). Our study clearly evidence that proteinuria is always deleterious to transplant outcome even at early follow up time point. Based on our results we suggest that, in the context of elderly 
donors and in the absence of acknowledged effective pharmacological tools, when other causes of proteinuria are excluded (e.g. cardiovascular diseases, infections, metabolic comorbidities), close monitoring of proteinuria should be repeatedly performed. Dealing with immunologic "low-risk" patients, where utility of protocol biopsy is still debated, the presence of proteinuria in the first year at a relatively low extent $(0.5 \mathrm{~g} /$ day $)$, even in the absence of donor specific antibodies, should suggest a careful evaluation of patients leading to for-cause biopsy. Utility of protocol biopsy in patients with nonstandard donor, even in the absence of risk factors, should be ascertained by further studies.

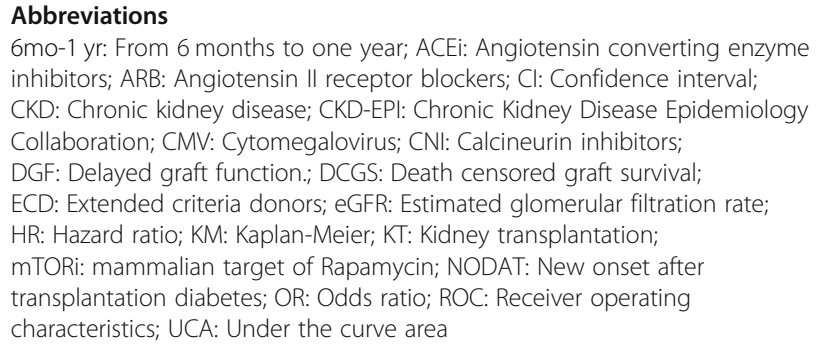

6mo-1 yr: From 6 months to one year; ACEi: Angiotensin converting enzyme inhibitors; ARB: Angiotensin II receptor blockers; Cl: Confidence interval; CKD: Chronic kidney disease; CKD-EPI: Chronic Kidney Disease Epidemiology Collaboration; CMV: Cytomegalovirus; CNI: Calcineurin inhibitors; DGF: Delayed graft function.; DCGS: Death censored graft survival; ECD: Extended criteria donors; eGFR: Estimated glomerular filtration rate; HR: Hazard ratio; KM: Kaplan-Meier; KT: Kidney transplantation; mTORi: mammalian target of Rapamycin; NODAT: New onset after transplantation diabetes; OR: Odds ratio; ROC: Receiver operating characteristics; UCA: Under the curve area

\section{Acknowledgments}

none.

\section{Authors' contribution}

D.D. Made substantial contribution to the conception and design of the work and made substantial contribution in the acquisition, analysis and interpretation of data; He has drafted the work or substantively revised it; M.M. Made substantial contribution to the conception and design of the work and has drafted the work or substantively revised it; C.D. Made substantial contribution in the acquisition, analysis and interpretation of data and has drafted the work or substantively revised it; F.F. Made substantial contribution in the acquisition, analysis and interpretation of data and has drafted the work or substantively revised it; E.S. Made substantial contribution in the acquisition and analysis of data; M.R. has drafted the work or substantively revised it; A.B. has drafted the work or substantively revised it; A.V. has drafted the work or substantively revised it; L.B. Made substantial contribution to the conception and design of the work and has drafted the work or substantively revised it.

All authors have approved the submitted version; all authors have agreed both to be personally accountable for the author's own contributions and to ensure that questions related to the accuracy or integrity of any part of the work, even ones in which the author was not personally involved, are appropriately investigated, resolved, and the resolution documented in the literature.

\section{Funding}

no specific funds have been retrieved for the present study.

\section{Availability of data and materials}

All relevant data are enclosed in manuscript or in table and figures. The datasets used and/or analysed during the current study are available from the corresponding author on reasonable request.

\section{Ethics approval and consent to participate}

The study was approved by the local ethics committee (The study was submitted and approved by the local ethics committee (ethics committee of "Azienda Ospedaliera Universitaria città della Salute e della Scienza di Torino"/University of Turin) and was performed in adherence with the last version of the Helsinki Declaration. All patients consented to have their clinical data collected for study purposes by written form.
Consent for publication

Not Applicable.

\section{Competing interests}

Authors have no issues related to journal policies and no potential competing interests.

\section{Author details}

${ }^{1}$ Renal Transplant Center "A. Vercellone", Nephrology, Dialysis and Renal Transplant Division, "Città della Salute e della Scienza Hospital", Department of Medical Sciences, University of Turin, Corso Dogliotti14, 10126 Torino, Italy. 2Division of Pathology, "Città della Salute e della Scienza Hospital",

Department of Medical Sciences, University of Turin, Turin, Italy. ${ }^{3}$ Department of Vascular Surgery, "Città della Salute e della Scienza Hospital", University of Turin, Turin, Italy.

Received: 12 July 2019 Accepted: 21 November 2019 Published online: 02 December 2019

\section{References}

1. Rosengard BR, Feng S, Alfrey EJ, Zaroff JG, Emond JC, Henry ML, et al. Report of the Crystal City meeting to maximize the use of organs recovered from the cadaver donor. Am J Transplant Off J Am Soc Transplant Am Soc Transpl Surg. 2002;2(8):701-11.

2. Frei U, Noeldeke J, Machold-Fabrizii V, Arbogast $H$, Margreiter R, Fricke L, et al. Prospective Age-Matching in Elderly Kidney Transplant Recipients-A 5-Year Analysis of the Eurotransplant Senior Program. Am J Transplant. 2007; O(0):071105081616014-???

3. Tullius SG, Tran H, Guleria I, Malek SK, Tilney NL, Milford E. The Combination of Donor and Recipient Age is Critical in Determining Host Immunoresponsiveness and Renal Transplant Outcome: Trans Meet Am Surg Assoc 2010;128:275-89.

4. Messina M, Diena D, Dellepiane S, Guzzo G, Lo Sardo L, Fop F, et al. Longterm outcomes and discard rate of kidneys by decade of extended criteria donor age. Clin J Am Soc Nephrol CJASN. 2017;12(2):323-31.

5. Matsushita K, Coresh J, Sang Y, Chalmers J, Fox C, Guallar E, et al. Estimated glomerular filtration rate and albuminuria for prediction of cardiovascular outcomes: a collaborative meta-analysis of individual participant data. Lancet Diabetes Endocrinol. 2015;3(7):514-25.

6. Naesens M, Lerut E, Emonds M-P, Herelixka A, Evenepoel P, Claes K, et al. Proteinuria as a noninvasive marker for renal allograft histology and failure: an observational cohort study. J Am Soc Nephrol JASN. 2016;27(1):281-92.

7. Halimi J-M, Laouad I, Buchler M, Al-Najjar A, Chatelet V, Houssaini TS, et al. Early low-grade proteinuria: causes, short-term evolution and long-term consequences in renal transplantation. Am J Transplant. 2005;5(9):2281-8.

8. Halimi J-M, Buchler M, Al-Najjar A, Laouad I, Chatelet V, Marlière J-F, et al. Urinary albumin excretion and the risk of graft loss and death in proteinuric and non-proteinuric renal transplant recipients. Am J Transplant Off J Am Soc Transplant Am Soc Transpl Surg. 2007;7(3):618-25.

9. Amer H, Fidler ME, Myslak M, Morales P, Kremers WK, Larson TS, et al. Proteinuria after kidney transplantation, relationship to allograft histology and survival. Am J Transplant. 2007;7(12):2748-56.

10. Amer H, Cosio FG. Significance and Management of Proteinuria in kidney transplant recipients. J Am Soc Nephrol. 2009;20(12):2490-2.

11. Amer H, Lieske JC, Rule AD, Kremers WK, Larson TS, Franco Palacios CR, et al. Urine high and low molecular weight proteins one-year post-kidney transplant: relationship to histology and graft survival. Am J Transplant Off J Am Soc Transplant Am Soc Transpl Surg. 2013;13(3):676-84.

12. Nauta FL, Bakker SJL, van Oeveren W, Navis G, van der Heide JJH, van Goor $\mathrm{H}$, et al. Albuminuria, proteinuria, and novel urine biomarkers as predictors of long-term allograft outcomes in kidney transplant recipients. Am J Kidney Dis Off J Natl Kidney Found. 2011;57(5):733-43.

13. Sancho Calabuig A, Pallardó Mateu LM, Avila Bernabeu Al, Gavela Martínez E, Beltrán Catalán S, Crespo Albiach JF. Very low-grade proteinuria at 3 months Posttransplantation is an earlier marker of graft survival. Transplant Proc. 2009;41(6):2122-5.

14. Cantarovich F, Martinez F, Heguilen R, Thervet E, Mamzer-Bruneel M-F, Gonzalez C, et al. Proteinuria $>0.5 \mathrm{~g} / \mathrm{d}$, a prevalent prognostic factor for patient and graft survival in kidney transplantation: kidney graft and proteinuria > 0.5 g/d. Clin Transpl. 2010;24(2):175-80. 
15. López V, Cabello M, Ruíz-Esteban P, Sola E, Gutiérrez C, Jironda C, et al. Impact of early low-grade proteinuria and allograft dysfunction on survival in expanded criteria donor kidney transplant recipients. Transplant Proc. 2015;47(9):2611-4.

16. Chapter 2: Definition, identification, and prediction of CKD progression. Kidney Int Suppl. 2013;3(1):63-72.

17. Telmisartan R. Or both in patients at high risk for vascular events. N Engl J Med. 2008;358(15):1547-59.

18. Jamerson K, Weber MA, Bakris GL, Dahlöf B, Pitt B, Shi V, et al. Benazepril plus amlodipine or hydrochlorothiazide for hypertension in high-risk patients. N Engl J Med. 2008;359(23):2417-28.

19. Kasiske BL, Zeier MG, Chapman JR, Craig JC, Ekberg H, Garvey CA, et al. KDIGO clinical practice guideline for the care of kidney transplant recipients: a summary. Kidney Int. 2010;77(4):299-311.

20. Borrego J, Mazuecos A, Gentil MA, Cabello M, Rodríguez A, Osuna A, et al. Proteinuria as a predictive factor in the evolution of kidney transplantation. Transplant Proc. 2013;45(10):3627-9.

21. Tsampalieros A, Knoll GA. Evaluation and Management of Proteinuria after Kidney Transplantation. Transplantation. 2015;99(10):2049-60.

22. Denic A, Glassock RJ, Rule AD. Structural and functional changes with the aging kidney. Adv Chronic Kidney Dis. 2016;23(1):19-28.

23. Glassock RJ, Rule AD. The implications of anatomical and functional changes of the aging kidney: with an emphasis on the glomeruli. Kidney Int. 2012;82(3):270-7.

24. Musso CG, Reynaldi J, Martinez B, Pierángelo A, Vilas M, Algranati L. Renal reserve in the oldest old. Int Urol Nephrol. 2011;43(1):253-6.

25. Fliser D, Ritz E, Franek E. Renal reserve in the elderly. Semin Nephrol. 1995; 15(5):463-7.

26. Dedov II, Mukhin NA, Shestakova MV, Paltzev MA, Warshawskyi VA, Severgina ES, et al. Renal functional reserve in diabetic patients without clinical nephropathy: comparisons with renal morphology. Diabet Med J $\mathrm{Br}$ Diabet Assoc. 1991;8 Spec No:S43-47.

27. Earle KA, Mehrotra S, Dalton RN, Denver E, Swaminathan R. Defective nitric oxide production and functional renal reserve in patients with type 2 diabetes who have microalbuminuria of African and Asian compared with white origin. J Am Soc Nephrol JASN. 2001;12(10):2125-30.

28. Verma V, Kant R, Sunnogrot N, Gambert SR. Proteinuria in the elderly: evaluation and management. Int Urol Nephrol. 2012;44(6):1745-51.

29. Karam G, Hétet J-F, Maillet F, Rigaud J, Hourmant M, Soulillou J-P, et al. Late ureteral stenosis following renal transplantation: risk factors and impact on patient and graft survival. Am J Transplant Off J Am Soc Transplant Am Soc Transpl Surg. 2006;6(2):352-6.

30. Palazzetti A, Oderda M, Dalmasso E, Falcone M, Bosio A, Sedigh O, et al. Urological consequences following renal transplantation: a review of the literature. Urol J. 2015;82(4):211-8.

31. Hariharan S, McBride MA, Cherikh WS, Tolleris CB, Bresnahan BA, Johnson CP. Post-transplant renal function in the first year predicts long-term kidney transplant survival. Kidney Int. 2002;62(1):311-8.

32. Kasiske BL, Israni AK, Snyder JJ, Skeans MA. Patient outcomes in renal transplantation (PORT) investigators. The relationship between kidney function and long-term graft survival after kidney transplant. Am J Kidney Dis Off J Natl Kidney Found. 2011:57(3):466-75.

33. Legendre C, Canaud G, Martinez F. Factors influencing long-term outcome after kidney transplantation. Transpl Int Off J Eur Soc Organ Transplant. 2014;27(1):19-27.

34. Nett PC, Heisey DM, Fernandez LA, Sollinger HW, Pirsch JD. Association of cytomegalovirus disease and acute rejection with graft loss in kidney transplantation. Transplantation. 2004;78(7):1036-41.

35. Reischig T, Kacer M, Hruba P, Jindra P, Hes O, Lysak D, et al. The impact of viral load and time to onset of cytomegalovirus replication on long-term graft survival after kidney transplantation. Antivir Ther. 2017;22(6):503-13.

36. O'Connell PJ, Kuypers DR, Mannon RB, Abecassis M, Chadban SJ, Gill JS, et al. Clinical trials for immunosuppression in transplantation: the case for reform and change in direction. Transplantation. 2017;101(7):1527-34.

37. Biancone L, David S, Della Pietra V, Montrucchio G, Cambi V, Camussi G. Alternative pathway activation of complement by cultured human proximal tubular epithelial cells. Kidney Int. 1994;45(2):451-60.

38. Noris M, Remuzzi G. Overview of complement activation and regulation. Semin Nephrol. 2013;33(6):479-92.

39. Baines RJ, Brunskill NJ. Tubular toxicity of proteinuria. Nat Rev Nephrol. 2011; 7(3):177-80
40. Erkan E, Devarajan P, Schwartz GJ. Mitochondria are the major targets in albumin-induced apoptosis in proximal tubule cells. J Am Soc Nephrol JASN. 2007;18(4):1199-208.

41. Gorriz JL, Martinez-Castelao A. Proteinuria: detection and role in native renal disease progression. Transplant Rev Orlando Fla. 2012;26(1):3-13.

42. Chen L, Boadle RA, Harris DC. Toxicity of holotransferrin but not albumin in proximal tubule cells in primary culture. J Am Soc Nephrol JASN. 1998;9(1): 77-84.

43. Opelz G, Zeier M, Laux G, Morath C, Dohler B. No improvement of patient or graft survival in transplant recipients treated with angiotensin-converting enzyme inhibitors or angiotensin II type 1 receptor blockers: a collaborative transplant study report. J Am Soc Nephrol. 2006;17(11):3257-62.

44. Ibrahim HN, Jackson S, Connaire J, Matas A, Ney A, Najafian B, et al. Angiotensin II blockade in kidney transplant recipients. J Am Soc Nephrol. 2013;24(2):320-7.

45. Knoll GA, Fergusson D, Chassé M, Hebert P, Wells G, Tibbles LA, et al. Ramipril versus placebo in kidney transplant patients with proteinuria: a multicentre, double-blind, randomised controlled trial. Lancet Diabetes Endocrinol. 2016;4(4):318-26.

46. Biancone L, Bussolati B, Mazzucco G, Barreca A, Gallo E, Rossetti M, et al. Loss of Nephrin expression in glomeruli of kidney-transplanted patients under m-TOR inhibitor therapy: m-TOR inhibitor and Nephrin expression. Am J Transplant. 2010;10(10):2270-8.

47. Pippias M, Jager KJ, Caskey F, Casula A, Erlandsson H, Finne P, et al. Kidney transplant outcomes from older deceased donors: a paired kidney analysis by the European renal association-European Dialysis and transplant association registry. Transpl Int Off J Eur Soc Organ Transplant. 2017 Dec;5.

48. Teppo A-M, Honkanen E, Finne P, Törnroth T, Grönhagen-Riska C. Increased urinary excretion of alpha1-microglobulin at 6 months after transplantation is associated with urinary excretion of transforming growth factor-beta1 and indicates poor long-term renal outcome. Transplantation. 2004;78(5): 719-24.

49. Hosaka B, Park SI, Felipe CR, Garcia RG, Machado PGP, Pereira AB, et al. Predictive value of urinary retinol binding protein for graft dysfunction after kidney transplantation. Transplant Proc. 2003;35(4):1341-3.

\section{Publisher's Note}

Springer Nature remains neutral with regard to jurisdictional claims in published maps and institutional affiliations.

Ready to submit your research? Choose BMC and benefit from:

- fast, convenient online submission

- thorough peer review by experienced researchers in your field

- rapid publication on acceptance

- support for research data, including large and complex data types

- gold Open Access which fosters wider collaboration and increased citations

- maximum visibility for your research: over $100 \mathrm{M}$ website views per year

At BMC, research is always in progress.

Learn more biomedcentral.com/submissions 